1 Williams G, Lofts F. Fuessl H, Bloom S. Treatment with danazol and plasma glucagon concentration. Br.11ed f 1985:291:1155-6.

2 Woodard TL, Burghen GA. Kitabchi AE. Wilimas JA. Glucose intolerance and insulin resistance in aplastic anaemia treated with oxsmetholone. 7 Clin Endocrnol Helab 1981:53:905-8.

Mallinson CN, Bloom SR. Warin AP. Salmon PR. Cox B. A glucagonoma svindrome. Lancet $1974:$ ii: $1-5$

+ Lefebvre PJ. Glucagon. Handhook of expermental pharmaiologv. Vol 66. Berlin: Springer Verlag, 1983.

5 W'ise JK. Hendler R. Felig P. Influence of glucocorticoids on glucagon secretion and plasma amino acid concentrations in man. 7 Clin Incest 1973:52:2774-882.

. 1.repled 25. Harih 1986

Department of Medicine, Hammersmith Hospital, London W12 0HS

GARETH WILLIAMS, MD, MRCP, RD Lawrence research fellow and honorary senior registrar

MOHA MMED GHATEI, PHD, senior research officer

JACKY BURRIN, PHD, principal biochemist

STEPHEN BLOOM, MD, FRCP, professor of endocrinology

Correspondence to: Professor Bloom.

\section{Where do lean diabetics inject their insulin? A study using computed tomography}

The aim of injecting insulin is to deposit the hormone in subcutaneous fat The lateral aspect of the thigh has been recommended as an injection site since the introduction of insulin treatment. For many years long needles were used, angled at about $45^{\circ}$, but recently shorter needles $(12-13 \mathrm{~mm})$ and a new injection technique were introduced. Most diabetics are recommended to use the perpendicular technique, inserting almost the whole enhanced computed tomography was performed with a GE 9800 scanner with a $512 \times 512$ matrix and a display field of view of $40 \mathrm{~cm}$, making the pixel size $0.78 \mathrm{~mm}$. Measurements were taken from skin surface to muscle, which we refer to as fat. Computed tomograms $1 \mathrm{~cm}$ thick were obtained immediately below the umbilicus and one third and two thirds of the distance from the inguinal ligament to the patella. Three measurements were made from each scan: lateral, intermediate, and medial.

The table shows the results. The lower part of the thigh had less subcutaneous fat, as expected, and data for that section are not included. The mean thickness of abdominal fat at the thickest point was $14 \mathrm{~mm}$ (range $4-26 \mathrm{~mm}$ ). Mean values for fat around the thigh were: lateral $6 \mathrm{~mm}$ (range $2-19 \mathrm{~mm}$ ), upper $8 \mathrm{~mm}$ (range $3-15 \mathrm{~mm}$ ), and medial $14 \mathrm{~mm}$ (range $4-25 \mathrm{~mm}$ ).

\section{Comment}

The striking finding in most patients was the thinness of the subcutaneous fat laver in the lateral aspect of the thigh. All patients except those with insulin pumps used the thigh as their injection site, and some of them were asked to insert their usual needle in their usual way. The result was intramuscular injection in many cases. These patients experienced no pain and had evidently been injecting intramuscularly for years, as, probably, have many lean diabetics. Another striking finding was the uneven distribution of fat: one woman (case 1) had $26 \mathrm{~mm}$ of abdominal fat, $25 \mathrm{~mm}$ of fat medially in the thigh, but only a meagre $5 \mathrm{~mm}$ laterally in the thigh. She was reasonably well endowed with fat except where she was supposed to inject her insulin. One man (case 14), who had had diabetes for 30 years and was very thin, had under $9 \mathrm{~mm}$ of subcutaneous fat in the abdominal area; in the lateral aspect of the thigh, however, he had $19 \mathrm{~mm}$ of fat. The fat was evenly distributed around the thigh and could not have been the result of localised lipohypertrophy.

These findings show that many diabetics of normal weight have a very thin layer of subcutaneous fat in the lateral aspect of the thigh, and many probably regularly inject intramuscularly, at least when using the modern technique - that is, a perpendicular injection with a $12-13 \mathrm{~mm}$ needle.

This study was aided by Becton Dickinson, Sweden.

Measurements of fat in the abdomen and thigh in 14 diabetics

\begin{tabular}{|c|c|c|c|c|c|c|c|c|c|}
\hline \multirow{2}{*}{$\begin{array}{c}\text { Case } \\
\text { No }\end{array}$} & \multirow[b]{2}{*}{ Sex } & \multirow{2}{*}{$\begin{array}{l}\text { Height } \\
(\mathrm{cm})\end{array}$} & \multirow{2}{*}{$\begin{array}{c}\text { Weight } \\
(\mathrm{kg})\end{array}$} & \multicolumn{3}{|c|}{ Abdominal fat (mm) } & \multicolumn{3}{|c|}{ Thigh fat (mm) } \\
\hline & & & & Lateral & Intermediate & Medial & Upper lateral quadrant & Upper middle line & Medial \\
\hline 1 & $\mathrm{~F}$ & 174 & 63 & 15 & & 26 & 5 & 7 & 25 \\
\hline 2 & M & 176 & 69 & 4 & 9 & 14 & 5 & 10 & 15 \\
\hline 3 & $\mathrm{~F}$ & 166 & 55 & 5 & 15 & 11 & 7 & 9 & 17 \\
\hline 4 & $M$ & 176 & 74 & 3 & 7 & 9 & 3 & 5 & 16 \\
\hline 5 & $\mathbf{M}$ & 177 & 76 & 9 & 18 & 20 & 12 & 7 & 18 \\
\hline 6 & $\mathbf{M}$ & 181 & 65 & 2 & 14 & 18 & 4 & 8 & 18 \\
\hline 7 & M & 178 & 67 & 3 & 10 & 12 & 3 & 15 & 13 \\
\hline 8 & M & 180 & 63 & 3 & 15 & & 2 & 5 & 10 \\
\hline 9 & M & 193 & 76 & 2 & 9 & 8 & 2 & 7 & 10 \\
\hline 10 & $M$ & 173 & 65 & 5 & 23 & 9 & 7 & 9 & 13 \\
\hline 11 & $\mathbf{M}$ & 178 & 66 & 8 & 5 & 5 & 2 & 8 & 14 \\
\hline 12 & M & 179 & 66 & 4 & 3 & 3 & 2 & 3 & 4 \\
\hline 13 & $\mathrm{~F}$ & 167 & 55 & 12 & 8 & 5 & 8 & 9 & 11 \\
\hline 14 & $M$ & 183 & 61 & 5 & 9 & 8 & 19 & 13 & 15 \\
\hline
\end{tabular}

length of the needle to ensure the same depth of injection every time. Very lean diabetics are instructed to angle the needle at about $45^{\circ}$. The risk of penetrating the muscle has been considered small. In this study we used computed tomography to investigate the subcutaneous fat layer in diabetics of normal weight.

\section{Patients, method, and results}

We studied 14 patients, three of whom were women. We assumed that the fat layer would be sufficient in most women and therefore concentrated on men. Two patients (one man and one woman) had type II diabetes and the rest had type I diabetes; all were being treated with insulin. Three of the patients had insulin pumps. All patients were in a state of good metabolic control, and none had a history of recent weight loss. Ages ranged from 22 to 60 (mean 39). Non-
1 Binder C. Absorption of injected insulin. Acta Pharmacol Toxicol Copenh 1969;27 (suppl 2):1-87. 2 Heine RJ, Sikkenk AC, Bilo HJG, et al. Comparison of two commonly used insulin injection techniques. Diabetic Medicine 1985;2:175-6.

3 Forkman L, Cornell E, Almér LO. En liten handbok för dig som injicerar insulin. (A handbook for injecting insulin.) Malmö, Sweden: Novo, 1984

(Accepted 27 March 1986)

Department of Medicine and Radiology, Hospital of Falun, Sweden

ANDERS FRID, MD, MB, medical specialist

BJÖRN LINDÉN, MD, radiology specialist

Correspondence and requests for reprints to: Dr Frid, Med Klin, Lasarettet, 79182 Falun, Sweden. 